\title{
Pre-orthodontic mucogingival surgery: an esthetical case report
}

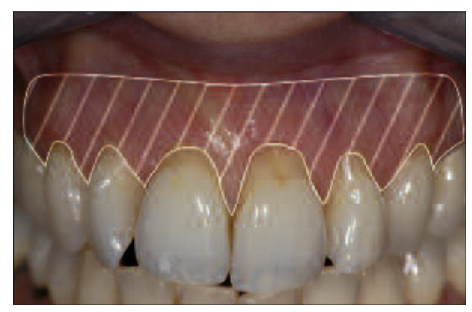

\author{
Sylvain LEYMARIE
}

\begin{abstract}
\section{KEY WORDS}

Mucogingival surgery,

Orthodontic treatment,

Case report.
\end{abstract}

If thickening of gingival soft tissue and root coverage are indicated, these two procedures should be performed prior to starting orthodontic treatment. The decision to initiate these treatments can be made only based on a clinically exact and reproducible diagnosis. The case described in this article is that of a 53-year-old woman presenting Miller Class III gingival recessions from 13 to 23 and 32 to 42 . Because of this impairment, she needs orthodontic treatment. The patient's periodontal biotype is thin.

The objective of the surgery discussed in this article is both to thicken the periodontium of the patient and to promote coverage of the recessions. To achieve these two objectives, we have chosen the modified "envelope" technique with insertion of connective tissue.

The 18 month post-operative results show an excellent rate of root coverage and a significant esthetic improvement of the gingiva.

\section{1 - INTRODUCTION}

The development of new orthodontic appliances, that are discreet or even completely undetectable, has encouraged a growing number of adults to benefit from treatment. Patients consult their orthodontists sometimes because of functional problems, but more often for esthetic reasons. Multi-disciplinary treatments are often

Conflict of interests declared by the author: NONE Article received: 12-2011. 
necessary to obtain a satisfying clinical result that improves appearance.

The goal of preventive mucogingival surgery is to increase soft tissue coverage before orthodontic treatment begins. In fact, treating gingival recessions is easier and more predictable if it is done before it becomes exacerbated $^{5}$. A gingival graft must be considered when buccal orthodontic movement of lower anterior teeth whose periodontal covering is delicate is likely to cause osseous dehiscence and subsequently, gingival reces$\operatorname{sion}^{8,3,5,9}$. If there is an observable defect present, a thickening procedure and a gingival graft must be performed before any orthodontic treatment can begin.

An accurate periodontal diagnosis can be made only after a detailed and reproducible clinical examination of the periodontium has been made. The results of this examination will lead directly to either initiating orthodontic treatment or to the two-step process of preliminary corrective therapy, then orthodontic treatment.

\section{1 - 1 - The pre-orthodontic periodontal diagnosis}

Periodontal diagnosis is an essential clinical step before starting orthodontic treatment, particularly, when the patient is an adult. Mainly, two types of periodontal pathologies are present: inflamed gingiva and deficient soft tissue.

Infectious inflammatory pathologies, such as gingivitis and period- ontitis, have to be treated thoroughly before and throughout orthodontic treatment. We do not deal with these two pathologies in this article.

But during the pre-treatment consultation orthodontists must discern the possible presence of two types of periodontal tissue defects, osseous and soft tissue. If there is generalized horizontal bone loss following an episode of periodontitis, the osseous supports are reduced and orthodontic treatment forces must be adapted to conform to them.

Bone defects, when they occur horizontally (fenestrations and dehiscences), are difficult to diagnose, even with tomodensitometry.

An examination of the superficial periodontium has three clinical components: the practitioner must check the thickness of the gingiva, the height of keratinized soft tissue, and finally the extent of gingival recessions.

We make a distinction between patients presenting a thick periodontal biotype and those with a thin periodontal biotype ${ }^{2}$ (Fig. 1).

The height of keratinized tissue is easily measured in millimeters with a periodontal probe. When it measures less than $3 \mathrm{~mm}$, it is considered insufficient.

Gingival recessions are identified according to the classification system described by Miller in $1985^{6}$ and divided into 4 categories:

- Class I: The periodontium is healthy (there is no erosion of the interproximal tissue and recessions do not exceed the line of the mucogingival margin; 

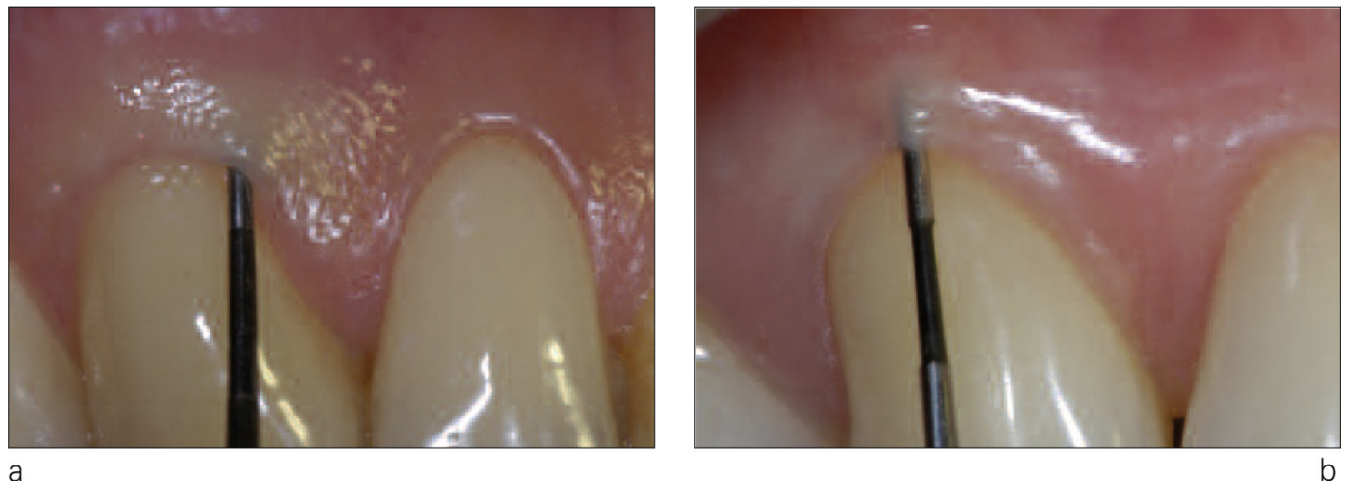

Figures $1 a$ and $1 b$

Thick periodontium on the left and thin on the right.

- Class II: the periodontium is healthy, and recessions exceed the line of the mucogingival margin;

- Class III: the periodontium is reduced (lack of interproximal tissue) and recessions do not exceed the line of the mucogingival margin;

- Class IV: the periodontium is reduced (lack of interproximal tissue) and recessions exceed the line of mucogingival margin.

\section{1 - 2 - Diagnostic criteria for choosing corrective therapy}

When an adult patient has recession of the gingiva and subsequently must have orthodontic treatment, different factors have to be taken into consideration.

\section{$1-2-1$ - The behavior of the patient}

The orthodontist must be certain that the patient is routinely controlling plaque (level of plaque below 20\%) but the patient must avoid excessive brushing and gingival trauma. If these two prerequisites are not satisfied and verified over a period of several months, the orthodontist should withhold treatment.

\section{1 - 2 - 2 - Clinical observations}

- The periodontal biotype.

- The quantity of residual keratinized tissue $(<3 \mathrm{~mm})$.

- The severity of the recession.

\section{$1-2$ - 3 - The subjective criteria of the patient}

- The presence of sensitivity at the site of the recessions is an indication that the orthodontist should try building up the soft tissue.

- If there is an esthetics problem directly related to the recessions.

In all cases, it is preferable to do plastic surgery before any orthodontic procedure in order to avoid worsening or creating a gingival defect.

The goal of this article is to present the periodontal treatment involved in a case that required a multi-disciplinary approach to restore and enhance gingival appearance. 


\section{2 - DESCRIPTION OF THE CASE AND RESULTS}

\section{2 - 1 - Diagnosis}

\section{2 - 1 - 1 - Periodontal diagnosis}

A non-smoking female patient, 53 years old and in good overall health came in the office for a periodontal check-up before receiving orthodontic treatment. As an adolescent, she had been treated by an orthodontist. Much later, 12 years before consulting us, she underwent a genioplasty that required orthognathic surgery but no orthodontic treatment. Despite these interventions, she still felt embarrassed by her teeth and her smile (Fig. 2).

She was afflicted with moderate chronic periodontitis and a Clinical Attachment Loss (CAL) varying from 3 to $5 \mathrm{~mm}$. The bone loss affected the first third of the roots of the upper molars and the first fourth of the root height in the other sectors (Fig. 3).

During the examination of the superficial periodontium, we noted:

- Class III Miller recessions from 13 to 23 and on 32 and 42 (Fig. 4);

- a thin periodontium;

- keratinized gingiva of $3 \mathrm{~mm}$ along the recessions.

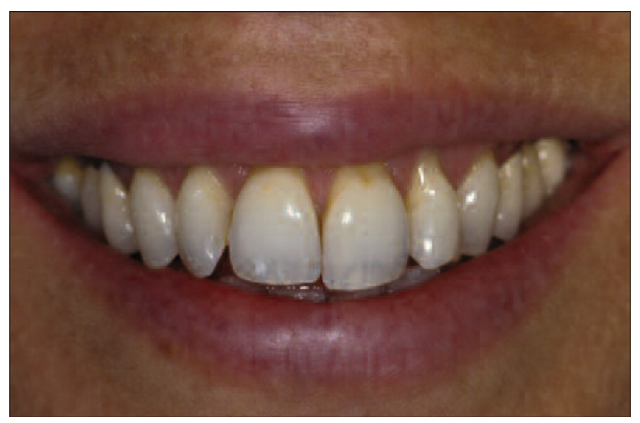

Figure 2 Initial smile.

\section{2- 1 - 2 - Diagnosis and orthodontic treatment plan}

This patient presented a Class II skeletal system with mandibular retrognathia in a hyperdivergent context a lower protrusion and atypical swallowing.

The patient had undergone a sliding genioplasty in order to hide the skeletal protrusion and to correct the vertical dimension.

We planned a lingual full banded/ bonded appliance using the Incognito ${ }^{\circledR}$ system.

15 will have to be extracted. 25 is the bridge pontic and 36 is absent; we then decided to extract the bridge pontic and to close the space in order to finish with a therapeutic Class II on the right side and in Class I on the left.

We'll use palatal mini-screws to help close the maxillary spaces as well for anchorage of Class II intermaxillary traction.

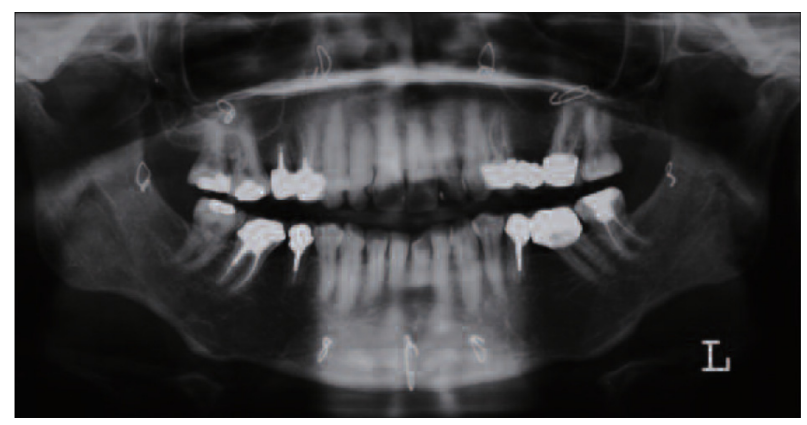

Figure 3 Initial panoramic film. 

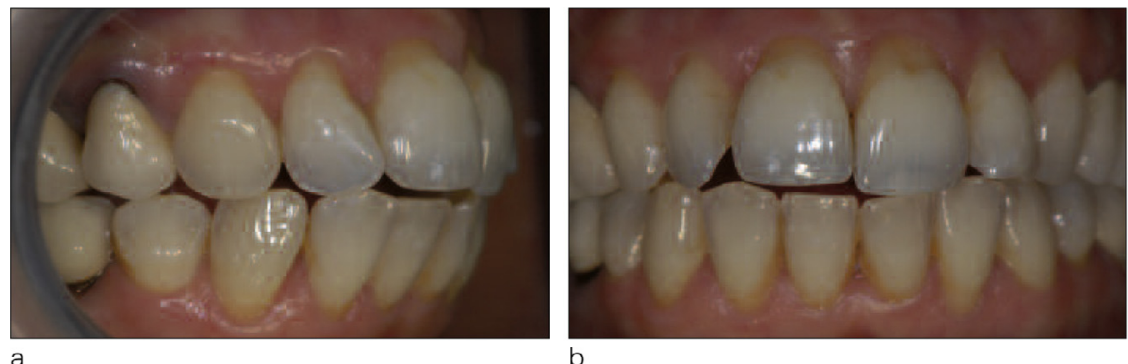

Figures $4 a$ to $4 c$

Pre-operative intraoral views.

\section{2 - 2 - Periodontal treatment}

\section{2-2 - 1 - Initial therapy}

After teaching the patient an atraumatic teeth brushing technique and establishing a routine of interdental brushing three times a day, we then had two office visits for tartar removal and root surface thickening that was done under anesthesia. We then carefully polished the teeth and prescribed a chlorexidine-based antiseptic mouthwash for one week.

Eight weeks later, a follow-up visit for periodontal reevaluation showed that the upper pockets were no more than $4 \mathrm{~mm}$ deep. The level of the patient's plaque was at $17 \%$. We then set up a periodontal therapy regimen: before each activation during orthodontic treatment, then routinely every 4 to 6 months.

\section{2- 2-2 - Maxillary surgical technique and therapy goal}

The therapeutic goal here is twofold: we want to modify the periodontal biotype of our patient, and to recover her recessions. The buried

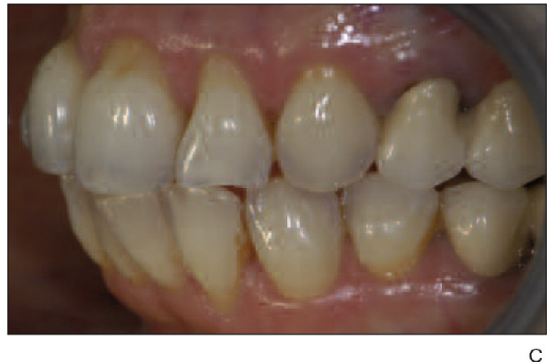




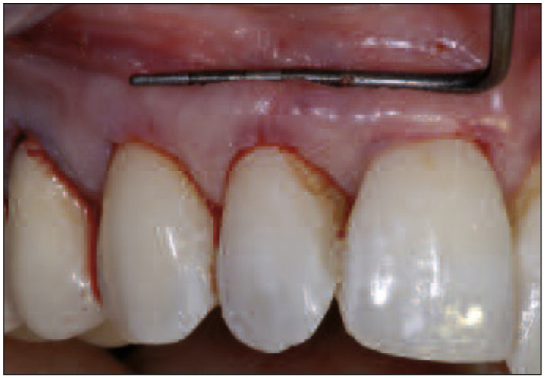

a

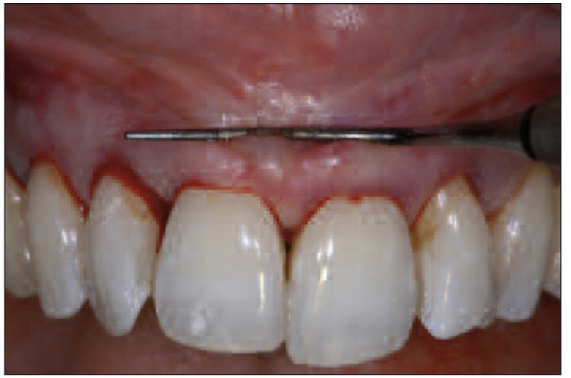

b

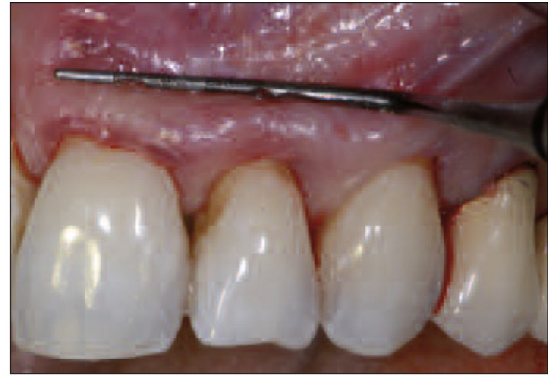

C

Figures $6 a$ to $6 c$

Liberation of the buccal gingiva after fabrication of the envelope.

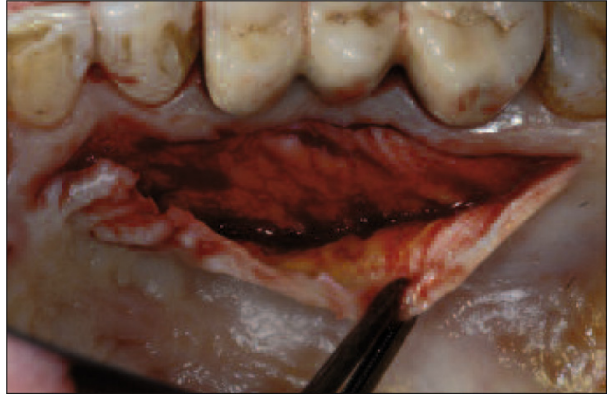

Figure 7

View of the subcutaneous conjunctive tissue collected after an envelope is made.

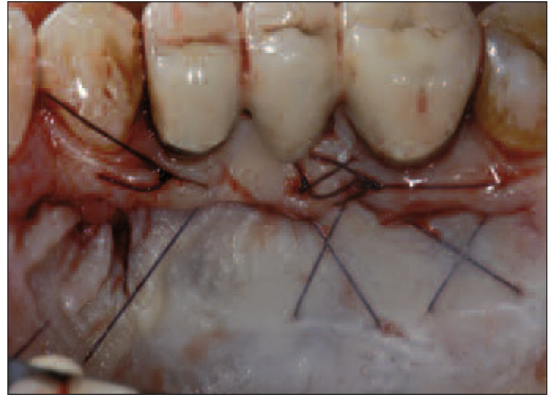

a

Figures $8 a$ and $8 b$

Palatal sutures after harvesting.

necks approximately $2 \mathrm{~mm}$ down A second incision is now made parallel to the palatal mucous lining, cutting into the first. The incision separates the palatal epithelium side that has sufficiently thick conjunctive tissue (1-2 $\mathrm{mm})$ from the underlying tissue side, and is then harvested with a stripper and blade (Fig. 7). This graft is taken at a distance from the vessel nerve bundle emerging from the oval foramen so as to avoid any neurological damage or hemorrhaging risks. The palatal flap is then sutured with cross-stitches (Fig. 8) and a surgical pad is placed along the entire palatal surface (Coe-Pack ${ }^{\circledR}$ ).
A first incision is made perpendicu-
larly to the surface of the palatal
mucous membrane along the dental

A first incision is made perpendicu-
larly to the surface of the palatal
mucous membrane along the dental

\section{- Taking a palatal graft}

The technique used here is the one described by Lorenzana and Allen in $2000^{4}$.

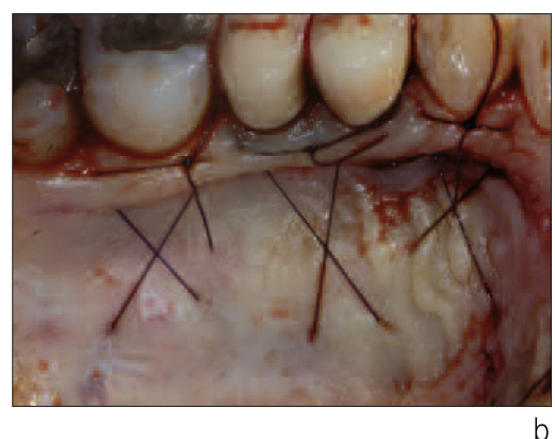

b

mucogingival margin. The papillae are also meticulously pulled back. Finally, with a curette, to completely free the tissue and to allow for its coronary this technique are twofold: it avoids unsightly scars and it preserves blood flow originating from the interdental papillae. 


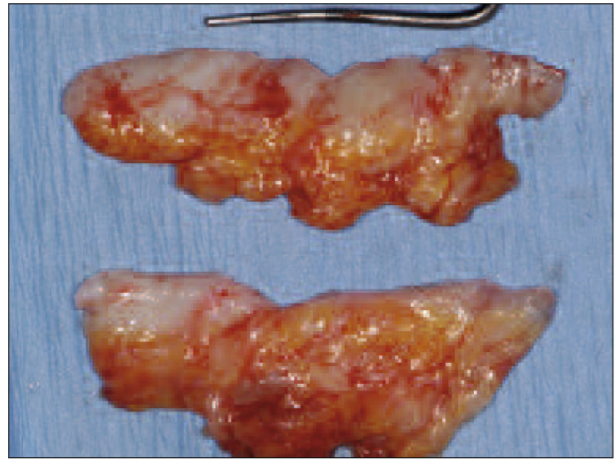

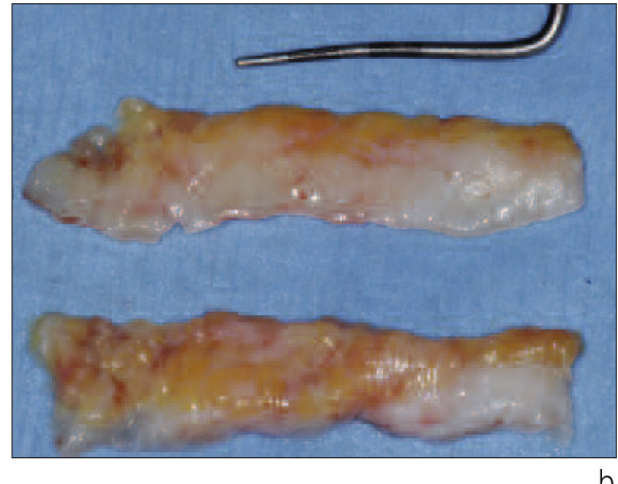

Figures $9 a$ and $9 b$

The collected and prepared graft material.
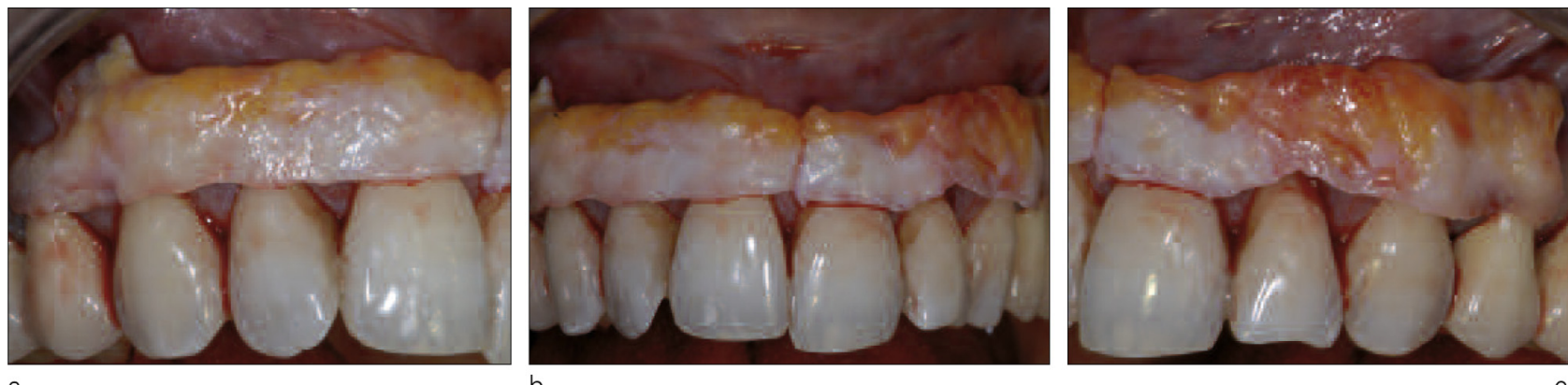

Figures 10a to $10 \mathrm{c}$

The graft material is placed at the site of insertion.

The collected graft material is defatted and cut to the desired length (Fig. 9).

\section{- Fitting the grafts}

The graft material is placed at the site of insertion (Fig. 10). The insertion is performed along the widest recessions: here, from 11 for the graft going from 11 to 13 , and from 21 for the graft going from 21 to 23 (Fig. 11). They are then sutured.

At this stage of the procedure, the first objective has been achieved: we have modified the biotype of our patient, from a thin periodontium to a thick periodontium, using a tissue graft (Fig. 12).

\section{- Coronary tractions of the grafts and envelops}

In order to reach our second objective, which is to try to rebuild coverage of the recessions, the buccal flap is loosely freed and the graft material is attached along the tooth neckline with vertical matrix sutures suspended from the interdental contact points, first held in place with a liquid composite (Fig. 13).

\section{2-2-3-Surgical technique for the mandible}

The technique used here, was described by Raetzke in 19857; we 


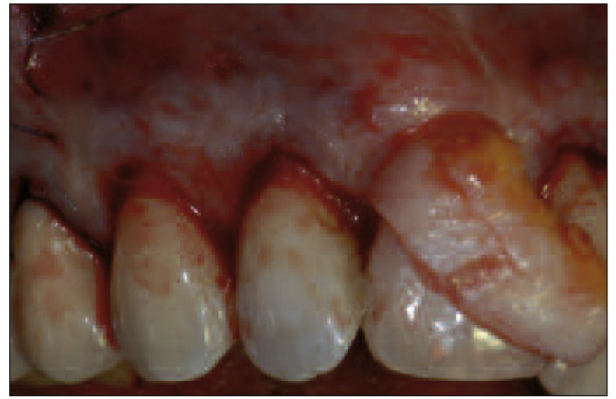

a

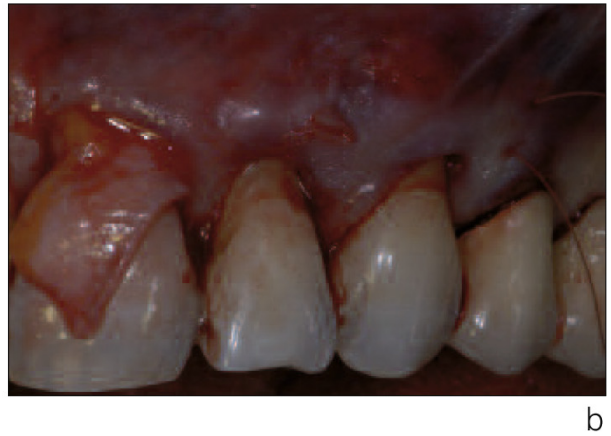

Figures 11a and $11 b$

Insertion of the graft material.
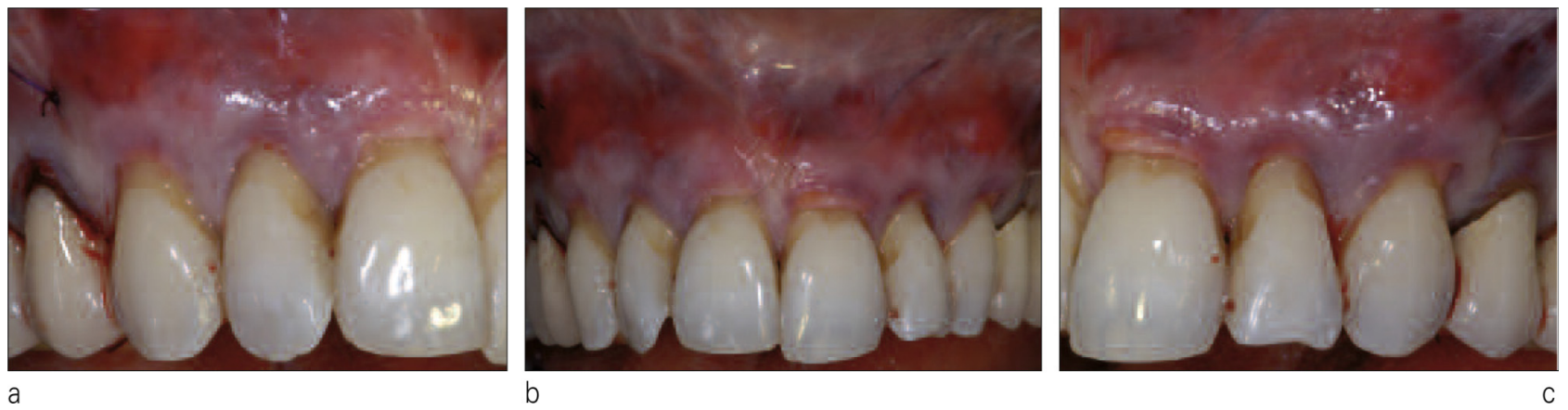

Figures $12 a$ to $12 \mathrm{c}$

Grafts sutures in place.
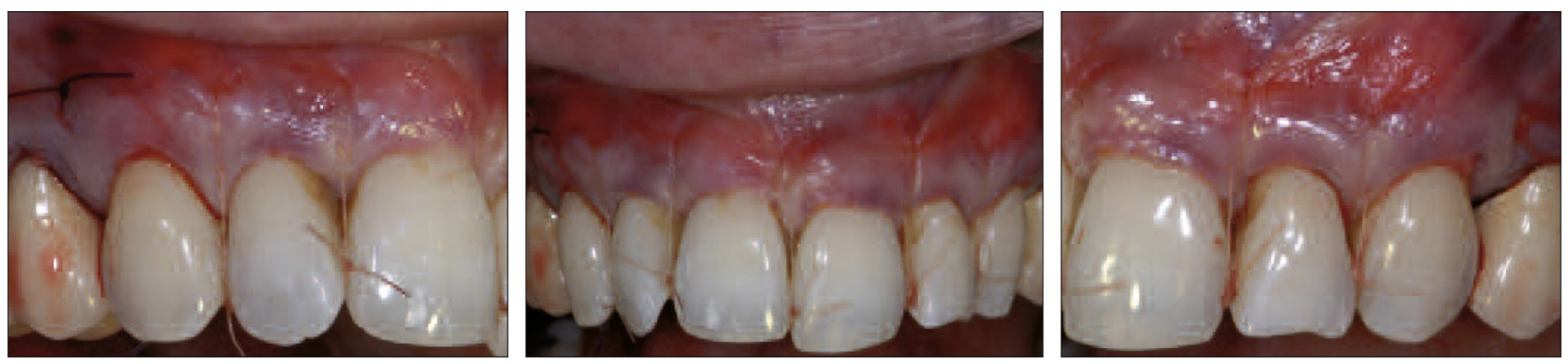

b

Figures $13 a$ to $13 c$

Grafts and envelope retracted. 

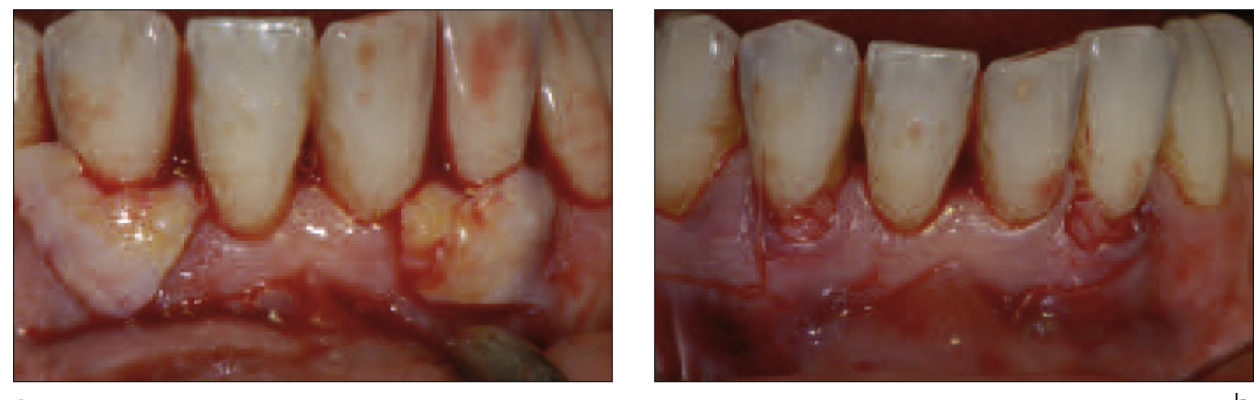

a

Figures $14 a$ and $14 b$

The grafts are slipped into their envelope and sutured.

have added sutures to this technique. It consists of sliding a graft of conjunctive tissue into an envelope first made in the vestibule of the treated tooth. A buccal suture transfixes the graft to the flap, which is not pulled back (Fig. 14).

\section{Prescription and post-operative follow-up}

- Prescription

- A steroidal derivative should be taken the morning of the procedure (prednisone $1 \mathrm{mg} / \mathrm{kg}$ in the morning for 4 days). It will reduce postoperative pain and edema.

- Analgesics, the first dose should be taken just before the procedure begins. During the $48 \mathrm{~h}$ following surgery, the patient should take the maximal dose (paracetamol with codeine or tramadol chlorhydrate or opium powder). Starting on the third day, the patient should stop the painkillers unless the symptoms persist. After stopping the prednisone (day 4), generally, ibuprofen and paracetamol can be combined as needed.

- antibiotics for the grafts (amoxicillin $1.5 \mathrm{~g}$ per diem for 7 days or azithromycin in case of allergic reaction) and antiseptic mouthwash (chlorexidine) starting on day 2.

Post-operative instructions play an important role in how the patient perceives discomfort and other consequences of surgery. The periodontist gives the instructions orally and also provides the patient with a checklist.

They deal with eating and dental hygiene and warn the patient of the possibility of varying jugal edema that can go as far as the lower eyelid, the possibility of bruising, and slight bleeding, etc.

\section{- Post-operative follow-up}

The patient was seen a week later, the intra-oral views show the presence of residual gingival edema (Fig. 15). Pads and palatal sutures are taken out.

The other sutures are taken out in two weeks. The result shown here is almost final (Fig. 16) and the palate is almost healed (Fig. 17). At 3 months, we schedule a prophylactic visit and then let orthodontists know that their treatment can begin. Therefore, we have attained our objectives of thickening the periodontium and re-covering the recessions (Fig. 18). 

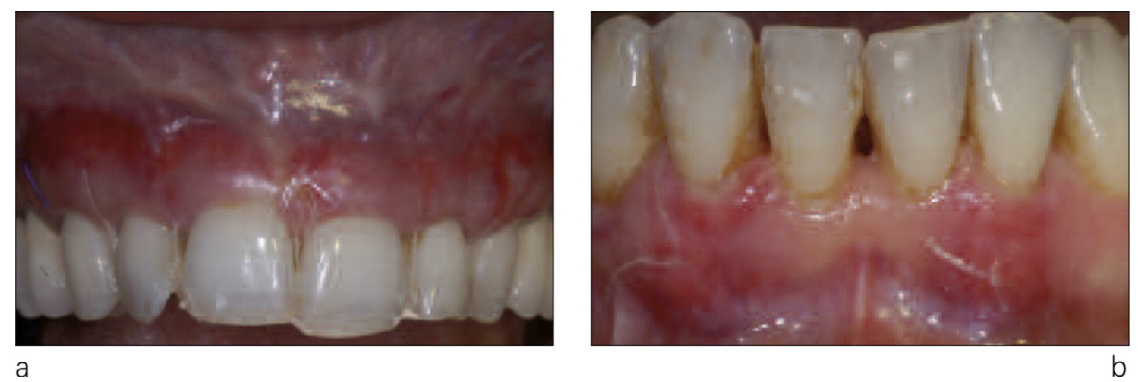

Figures $15 a$ and $15 b$

Results at one week.
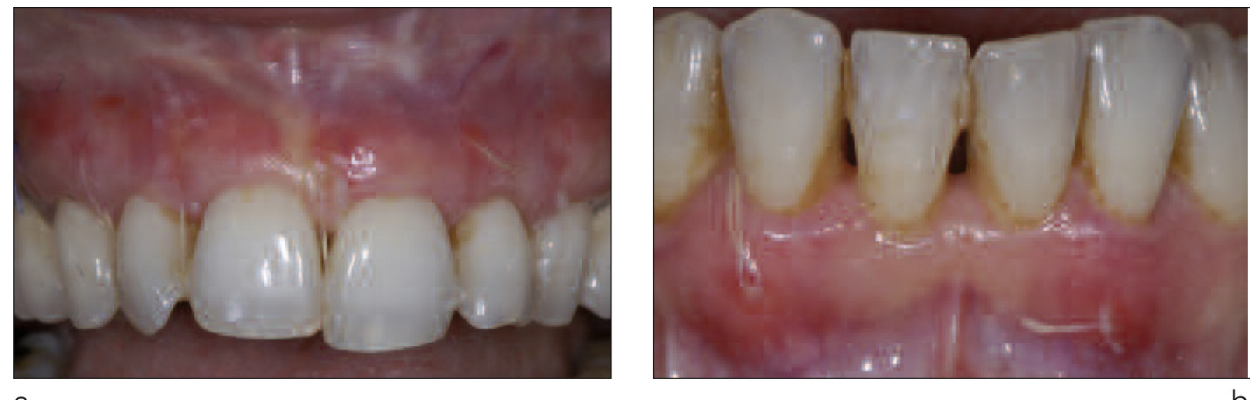

a

Figures $16 a$ and $16 b$

At 2 weeks, the final result has almost been obtained.
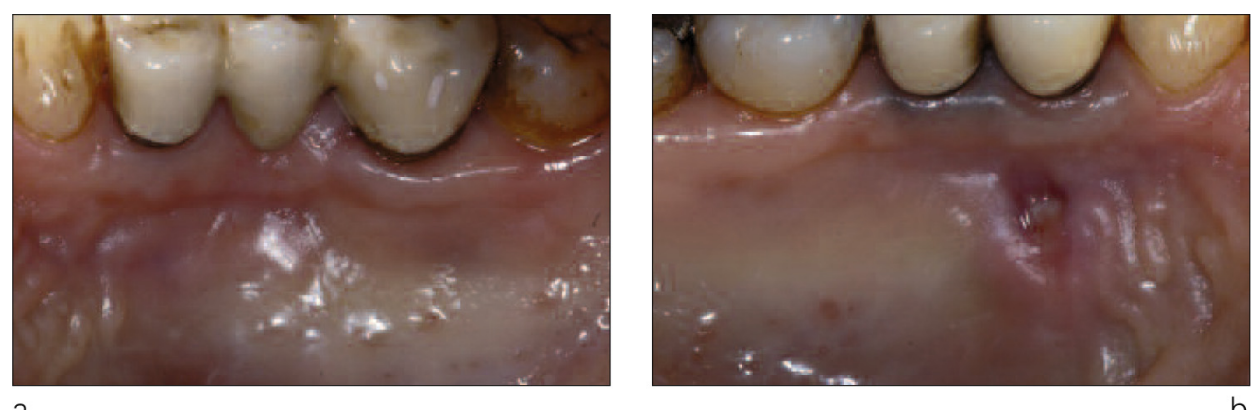

a

Figures $17 a$ and $17 b$

Healing of the palate at 2 weeks.

Throughout the duration of orthodontic treatment, a complete prophylaxis was done before each procedure. This consisted of a periodontal probe exam, supra and infra-gingival tartar removal and careful polishing. 18 months after surgery, the tissue has completely matured and the coverage of the recessions is satisfactory (Fig. 19). 


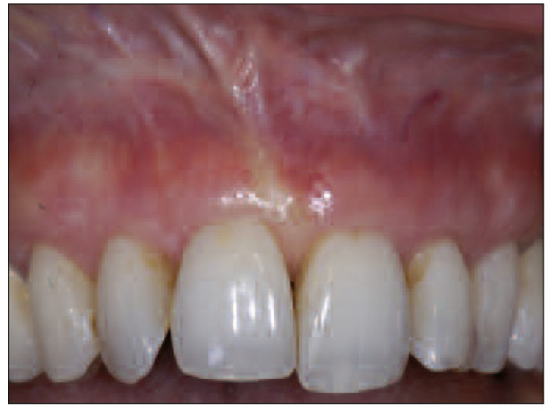

a

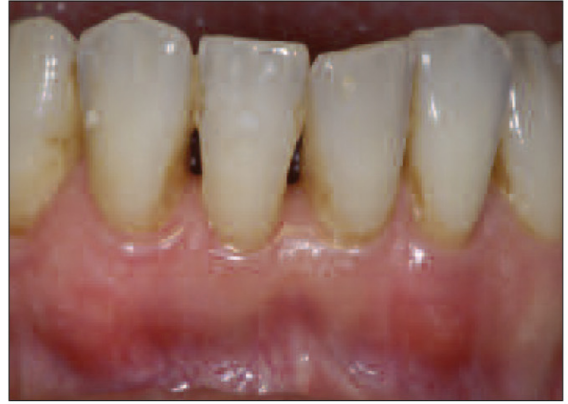

b

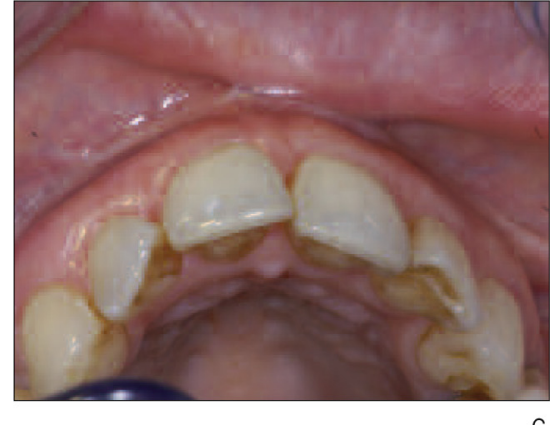

C

Figures 18a to $18 \mathrm{c}$

3 months after surgery, the healing is sufficient to initiate orthodontic treatment. Notice the thickening of the buccal periodontium.

a

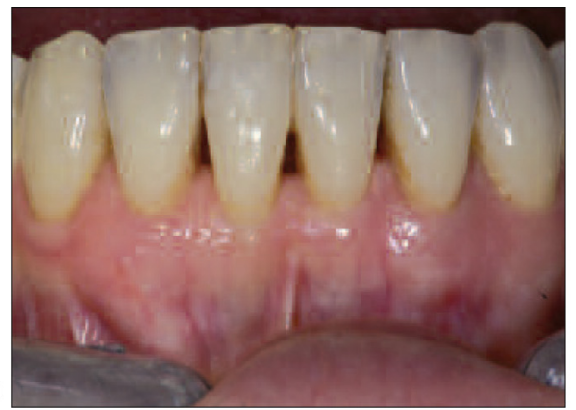

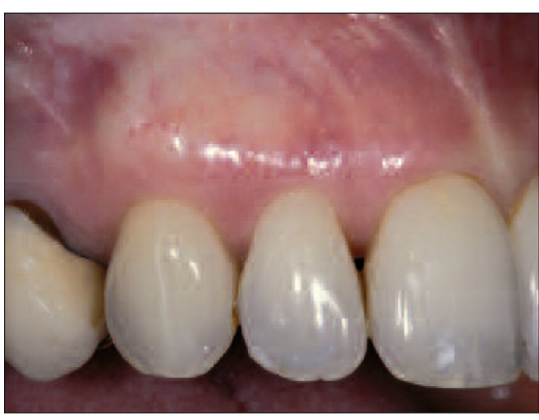

b

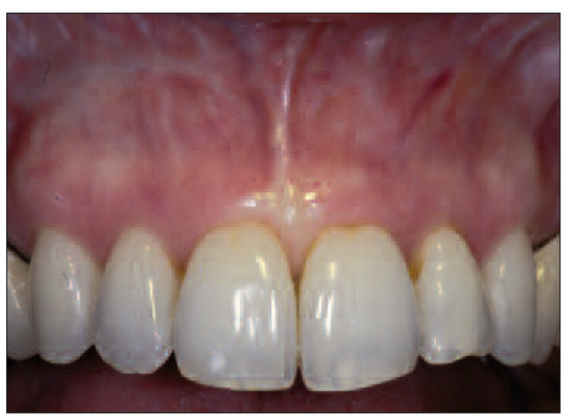

C

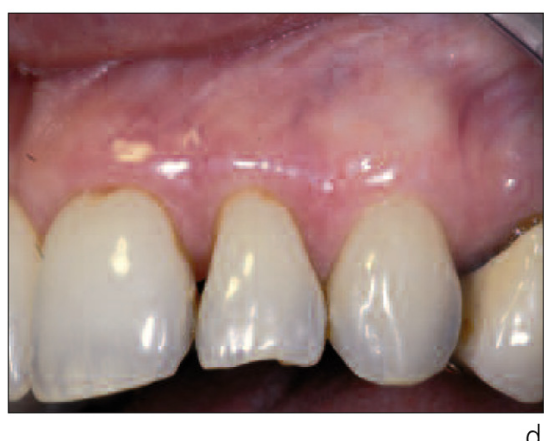

d

Figures 19a to $19 d$

Intraoral views 18 months after surgery; orthodontic treatment has been going on for 15 months. Coverage is now satisfactory. The absence of papillae persists between 11 and 12, and between 21 and 22.

\section{$3-$ CONCLUSION}

Today, periodontal plastic surgery has developed techniques that allow for predictable treatment for Class I and Class II recessions. This case demonstrates that even for Class III lesions, there can be good clinical results and improved esthetics. 

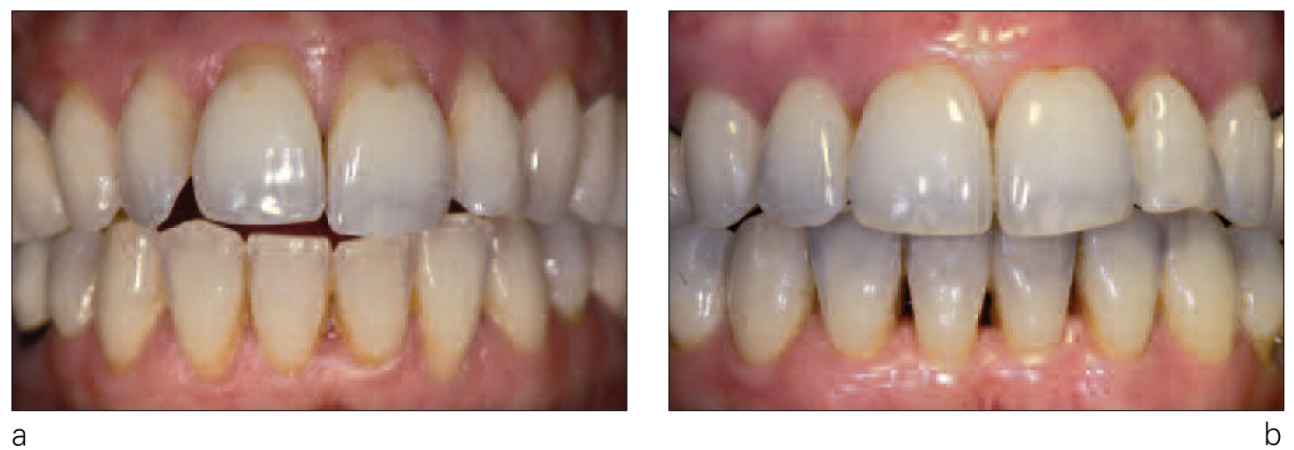

a

Figures 20a and $20 b$

Comparison of before and after treatment.

It presently seems reasonable to modify the biotype of our patients and to treat recessions before any orthodontic procedures, not only because it prevents the onset of a lesion and obviates a possible worsening of the biotype, but also because it preserves the integrity of deep periodontium.

\section{REFERENCES}

1. Azzi R, Etienne D. Recouvrement radiculaire et reconstruction papillaire par greffon conjonctif enfoui sous un lambeau vestibulaire tunnélisé et tracté coronairement. J Parodontol Implant Orale 1998; 17:71-7.

2. De Rouck T, Eghbali R, Collys K, De Bruyn H, Cosyn J. The gingival biotype revisited: transparency of the periodontal probe through the gingival margin as a method to discriminate thin from thick gingiva. J Clin Periodontol 2009;36(5):428-33.

3. Foushee DG, Moriarty JD, Simpson DM. Effects of mandibular orthognathic treatment on mucogingival tissue. J Periodontol 1985;56(12):727-33.

4. Lorenzana ER, Allen EP. The single incision palatal harvest technique : a strategy for esthetics and patient comfort. Int J Periodontics Restorative Dent 2000;20(3):297-305.

5. Maynard JG. The rationale for mucogingival therapy in the child and adolescent. Int $J$ Periodontics Restorative Dent 1987;7(1):36-51.

6. Miller PD Jr. A classification of marginal tissue recession. Int J Periodontics Restorative Dent 1985; 5(2):8-13.

7. Raetzke PB. Covering localized areas of root exposure employing the "envelope" technique. J Periodontol 1985;56(7):397-402.

8. Steiner GG, Pearson JK, Ainamo J. Changes of the marginal periodontium as a result of labial tooth movement in monkeys. J Periodontol 1981;52(6):314-20.

9. Wennström JL, Lindhe J, Sinclair F, Thilander B. Some periodontal tissue reactions to orthodontic tooth movement in monkeys. J Clin Periodontol 1987;14(3):121-9. 